\title{
Inhaltsverzeichnis des 2. Teiles
}

\section{Allgemeiner Teil (Fortsetzung)}

Lebensweise ..................... 5

Umwelt und Lebensraum $\ldots \ldots \ldots \ldots \ldots \ldots, 5$

Lebensstätte $\ldots \ldots \ldots \ldots \ldots \ldots \ldots \ldots \ldots \ldots, 12$

Tätigkeit $\ldots \ldots \ldots \ldots \ldots \ldots \ldots \ldots \ldots \ldots \ldots \ldots \ldots \ldots \ldots$

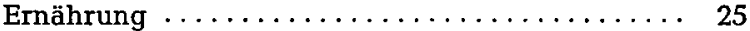

Feindvermeiden und -abwehr........... 30

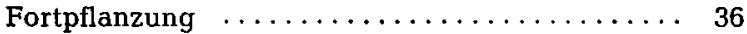

Jungenpflege $\ldots \ldots \ldots \ldots \ldots \ldots \ldots \ldots \ldots, 49$

Lebensdauer $\ldots \ldots \ldots \ldots \ldots \ldots \ldots \ldots \ldots \ldots, 60$

Gemeinschaftsleben $\ldots \ldots \ldots \ldots \ldots \ldots \ldots \ldots, 61$

Verhalten $\ldots \ldots \ldots \ldots \ldots \ldots \ldots \ldots \ldots \ldots, 67$

Wanderungen $\ldots \ldots \ldots \ldots \ldots \ldots \ldots \ldots \ldots \ldots$

Verbreitung $\ldots \ldots \ldots \ldots \ldots \ldots \ldots \ldots \ldots \ldots, 92$

Faunenreiche $\ldots \ldots \ldots \ldots \ldots \ldots \ldots \ldots \ldots, 92$

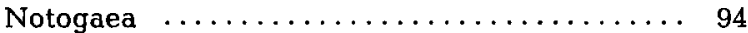

Neogaea $\quad \ldots \ldots \ldots \ldots \ldots \ldots \ldots \ldots \ldots \ldots \ldots, 98$

Arctogaea ....................... 100

Holarktis ...................... 103

Athiopische Region ................. 107

Orientalische Region $\ldots \ldots \ldots \ldots \ldots \ldots \ldots \ldots 114$

Arktis und Antarktis . . . . . . . . . . . 121

Fledertiere $\ldots \ldots \ldots \ldots \ldots \ldots \ldots \ldots \ldots \ldots \ldots 123$

Seekühe $\ldots \ldots \ldots \ldots \ldots \ldots \ldots \ldots \ldots \ldots \ldots, 126$

Robben $\ldots \ldots \ldots \ldots \ldots \ldots \ldots \ldots \ldots \ldots \ldots \ldots \ldots$

Wale $\ldots \ldots \ldots \ldots \ldots \ldots \ldots \ldots \ldots \ldots \ldots \ldots 128$

Vergleich der Faunenreiche $\ldots \ldots \ldots \ldots \ldots \ldots 131$

Australien und Ozeanien $\ldots \ldots \ldots \ldots \ldots \ldots \ldots 131$

Süd- und Mittelamerika ............... 133

Nordamerika und Eurasien . . . . . . . . . . . 134

Afrika und Madagaskar . . . . . . . . . . . 136

Südasien $\ldots \ldots \ldots \ldots \ldots \ldots \ldots \ldots \ldots \ldots \ldots \ldots \ldots$

Systematischer Teil .................... 138

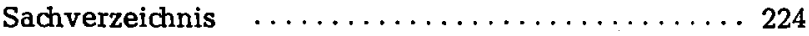




\section{Inhaltsverzeichnis des 1 . Teiles}

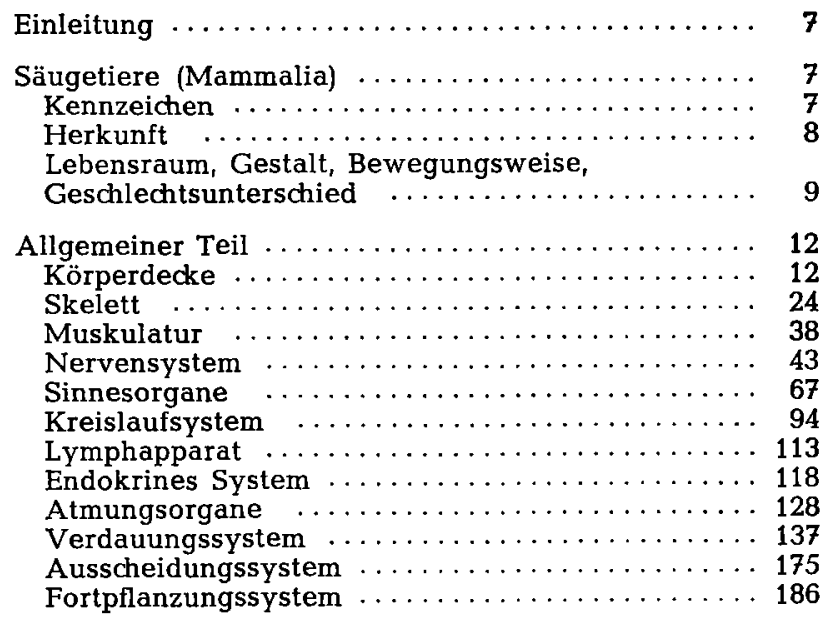

